\title{
Smart Growth: A Modern Urban Principle
}

\author{
Ritu Shrivastava*, Anupama Sharma \\ Department of Architecture and Planning, MANIT, Bhopal, 462051, India
}

\begin{abstract}
The concept of smart growth proponent's compact, transit-oriented, walkable surroundings that incorporates mixed land use pattern, including neighbourhood schools, retail and commercial space, community institutions, and a wide variety of housing types and styles, within close proximity of one another. It has been bestowed in various urban and suburban areas throughout the United States and has been found to beneficially affect natural habitats, air and water pollution, and the preservation of land.

The ideas and principles of smart growth are to gain a particular function of community and place; expand the range of transportation, employment, and housing choices; equally distributing the costs and benefits of development; preserve and enhance natural and cultural resources; and promote public health.
\end{abstract}

Keywords Compact Neighbourhoods, Mixed Land Use, Transit Oriented Development, Healthy Communities

\section{Introduction}

Smart growth is an wide urban generated planning and transportation theory that imparts growth in the centre of a city to decrease the urban sprawl; and creates compact, transit-oriented, walkable, bicycle-friendly land use, including neighbourhood schools, complete streets, and mixed-use development with a huge range of housing choices.

Smart growth recognizes connections between development and quality of life. It leverages new growth to improve the community. The features and idea of smart growth in a community differs from place to place. In general scenario, smart growth invests time, attention, and resources in community and provides new life to centre cities and older deteriorated areas. New smart growth is more influenced towards town-centred policy, transit and pedestrian oriented, and has a greater mix of housing, commercial and retail uses. It also preserves open space and many other environmental amenities.

\section{Why Need of Smart Growth}

Now day's cities are facing new challenges in accomplishing economic growth, increasing wealth, and improving quality of life for residents. Growth and development both are very necessary for the developing communities'. They enhance a new life and vitality to the complete scenario. Growth and development, if managed improperly, can

* Corresponding author:

ritu.archi@gmail.com (Ritu Shrivastava)

Published online at http://journal.sapub.org/arch

Copyright (C) 2011 Scientific \& Academic Publishing. All Rights Reserved negatively affect a community's quality of life, leading to congestion, pollution, pedestrian-hostile neighborhoods, and sprawl. To accommodate an increasing population and demand for housing, services and infrastructure, there is an urge for a complete revolutionized smart growth technique without upsetting the qualities that make their communities pleasant places to live and work.

\section{Components of Smart Growth}

Smart Growth America, a national coalition of multiple smart growth advocacy groups lists the following six goals of smart growth:

1. Neighbourhood livability

2. Better access/less traffic

3. Enabling pre-existing cities, suburbs, and towns to thrive

4. Shared benefits

5. Lower costs/lower taxes

6. Preserving open space

In accordance with these six goals, the Smart Growth Network has developed ten basic principles to achieving smart growth:

1. Mix land uses

2. Take advantage of compact building design

3. Create a range of housing opportunities and choices

4. Create walkable neighbourhoods

5. Foster distinctive, attractive communities with a strong sense of place

6. Preserve open space, farmland, natural beauty, and critical environmental areas

7. Strengthen and direct development towards existing communities

8. Provide a variety of transportation choices 
9. Make development decisions predictable, fair, and cost effective

10. Encourage community and stakeholder collaboration in development decisions

These goals and principles of Smart Growth as presented to the general public and planners may vary by context and location, thoughts and respective views, however several themes keeps on emerging which includes a range of: preservation of open space, protection of environmentally sensitive areas, and support for further development of existing urban areas .

The three commuting forces behind the idea of smart growth are the creation of compact neighbourhoods, a successful combination of multiple uses, and an emphasis on transit-oriented development.

\subsection{Compact Neighbourhoods}

There are many theories and assumptions behind smart growth concept but according to smart growth theorists, creating compact, livable and workable urban neighbourhoods will attract more residents, businesses it will act as a key element of reducing urban sprawl and protecting local environments and climates. This concept is often is gained by including a number of factors which are mixed-use development, the inclusion of affordable housing, public park and recreation space (to encourage pedestrian activity), and restrictions design forms (such as detached homes, private lots, large backyards, strip malls, and expansive surface parking lots). By concentrating activity in smaller, denser areas, smart growth preserves open spaces, reuses already-developed land in a more productive and refined manner, and harbors cleaner air, water supplies and other day to day utilities.

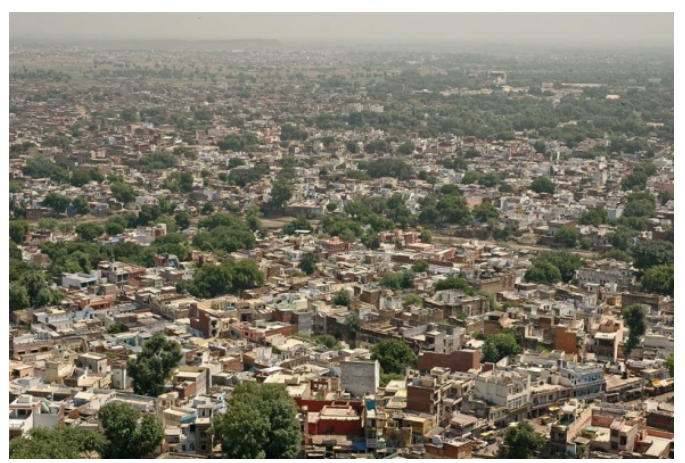

Figure 1. A view of compact neighborhood

\subsection{Mixed-Use Developments}

Mixed-use developments are design to include a complete designed lot which includes or enable a variety of different activities within the same defined area or vicinity. These developments often include a combination of residential, commercial, industrial, retail, educational, institutional, and recreational uses, and can vary in size from a single building to a large scale planned community. The main motive of mixed-use developments is decrease the large travel distance and activities should be in proximity to one another

In recent years, many large communities have focused on creating new "town centres" mixing multi-family residences, retail shops, and office space in order to maximize the use and profitability of land and increase the tax base of their municipalities.

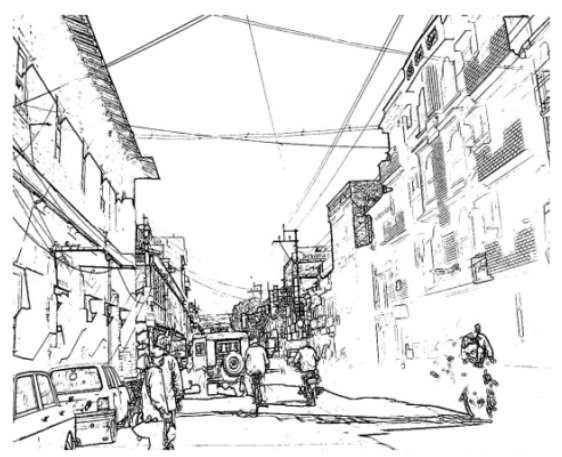

Figure 2. A view of mixed use pattern (residential cum commercial)

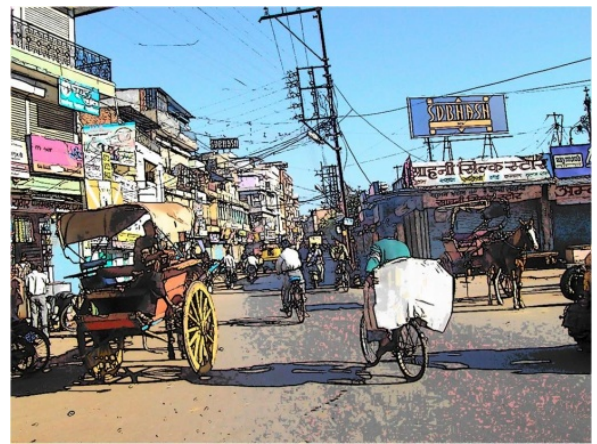

Figure 3. Mixed use development of a core historic area

\subsection{Transit-Oriented Development}

Transit-oriented developments are basically built around major transportation nodes; most frequently rail stations, but primary access between buses, highways, and park-and-ride lots as well. In addition to their focus on mass transit forms (i.e. commuter rail, light rail, bus rapid transit, etc) which are more environmentally-friendly than personal automobile travel, transit-oriented developments are also heavily oriented around biking and walking, which also reduces harmful 'population overall. Pedestrian- and bicycle-friendly improvements include narrower streets, bicycle lanes, an urban bike-trail system, bicycle parking, an emphasis on pedestrian crossings, and separated walking paths.

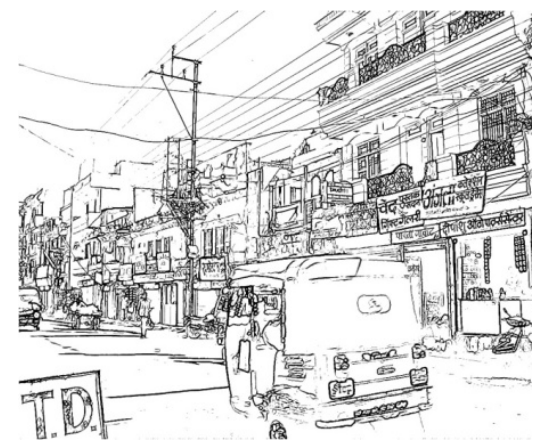

Figure 4. Transit oriented view of a core area 


\section{How Do Governments Affect Smart Growth}

Local governments affect smart growth development by local policies and zoning ordinances. Through zoning regulations, new development can be specified to a certain areas and land uses can be regulated by location. Zoning laws can also reduce the amount of parking required to be built with new development, and can be used to mandate land to be utilized for parks, recreation space, and other community amenities.

Another popular approach is the use of environmental impact assessments (EIA), often required of prospective developers by state and/or local governments. These reports bind the physical and social impact which new development will have on the surrounding communities and environment and how they can be minimized.

\section{Environmental Benefits of Smart Growth}

The United States Environmental Protection Agency claims, "Smart growth principles can minimize air and water pollution, encourage Brownfield's clean-up and reuse, and preserve natural lands.

A number of EPA studies performed across the United States have shown that applying smart growth principles to pre-existing communities has improved air quality (by reducing automobile mileage and emissions), improved water quality (by minimizing paved surfaces and enabling natural rainwater filtration devoid of contamination), and preserved a significant amount of open space and natural lands. Such case studies and evaluations have taken place in locations including Sacramento, Nashville, Atlanta, Southern New Jersey, Seattle, Denver, San Francisco/Oakland, Cleveland, Pittsburgh, Providence, Northern Virginia, Orlando, and Chicago.

\section{Obstacles to Smart Growth}

Also, smart growth developments are often far more costly (financially) for developers than typical suburban communities. There is more dependency on automobiles rather than being pedestrianised environment. The availability of chunk of land as per feasibility and location is also in more deficient ratio. Therefore, much smart growth often occurs in the form of urban infill or urban redevelopment, which is often expensive and controversial. Pre-existing neighbourhood residents also often protest massive new developments. Furthermore, mass transit growth and expansion is similarly controversial and expensive. In addition, many critics claim that the rigidity of smart growth plans increases personal regulations and reduces freedom, and that the density of smart growth developments may actually increase traffic congestion.

\section{Conclusions}

Ultimately, the design and development of an area are correlated to and it has a wider range of affects on many other aspects such as the environment, sustainability, consumption, transportation, population and lifestyle. A well designed town with the needs of residents in mind can create a more stable and equitable area. Additionally, and important lesson which should be always kept is that the shape of communities and smart growth can be transformed by the residents. People want to live in an environment and a world capable of sustainability. "Smart urban growth" offers a better design that also benefits the environment, ecology, economy, equity, which can help provide better lives for the entire nation and the world. It will lead to a complete "Livable Community".

\section{Further Readings:}

1. Smart Growth America

2. Coalition for Smarter Growth

3. Bullard, Robert D. (ed.) (2007). Growing Smarter: Achieving Livable Communities, Environmental Justice, and Regional Equity. The MIT Press. ISBN 978-0-262-524704

4. "Urban Alchemy" Article about the need for efficient transit to serve smart growth

\section{External Links:}

1. Smart Growth Planning

2. Smart Code 7.0 A model for New Urbanism Planning Codes in PDF Format

3. Smart Growth America organization

4. Coalition for Smarter Growth

5. Smart Growth Online

\section{REFERENCES}

[1] Wikipedia: Smart Growth

[2] Litman, Todd. Evaluating Criticism of Smart Growth. Victoria Transport Policy Institute. 24 September 2007.

[3] Conflicts Between Smart Growth and Housing Affordability

[4] O'Toole, Randall. The Folly of "Smart Growth" Thoureau Institute.

[5] Smart Growth and Its Effect on Housing Markets: The New Segregation. (National Center for Public Policy Research)

[6] Burchell, Robert W., David Listokin, and Catherine C. Galley. Smart Growth: More Than a Ghost of Urban Policy Past, Less Than a Bold New Horizon. Housing Policy Debate. Rutgers, the State University of New Jersey (821-879).

[7] About Smart Growth (U.S. EPA)

[8] Environmental Benefits of Smart Growth (U.S. EPA)

[9] Effects of Different Development Types on the Environment (U.S. EPA)

[10] This is Smart Growth: Featured Communities 
[11] Moglen, Glenn E., Steven A. Gabriel, and Jose A. Faria. A Framework for Quantitative Smart Growth in Land Development. Journal of the American Water Resources Association. August 2003 (947-959).

[12] What is Smart Growth? (Smart Growth America)

[13] Knaap, Gerrit-Jan. A Requiem for Smart Growth? National

\section{Center for Smart}

[14] Growth Research and Education. University of Maryland.

[15] Arlington County, Virginia (U.S. EPA)

[16] Miller, Nancy A. and Jeff Miller. Defining Mixed-Use Development. University of Minnesota. 